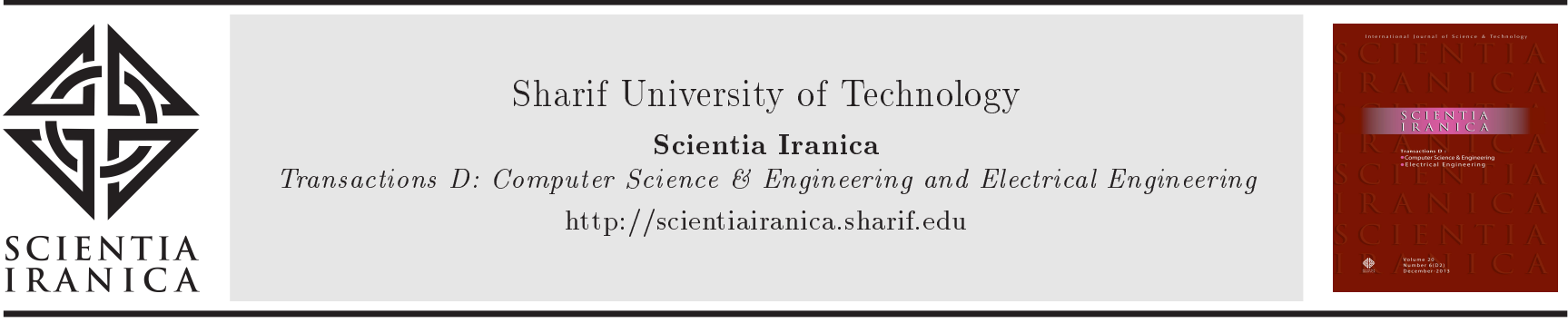

\title{
An application of energy efficiency programs to multi-stage transmission network expansion and reactive power planning
}

\author{
A. Mahmoudabadi ${ }^{a}$, M. Rashidinejad ${ }^{\mathrm{b}, *}$, and A. Abdollahi ${ }^{\mathrm{b}}$ \\ a. Electrical and Computer Engineering Department, Graduate University of Advanced Technology, Kerman, Iran. \\ b. Electrical Engineering Department, Shahid Bahonar University of Kerman, Kerman, Iran. \\ Received 25 September 2019; received in revised form 4 February 2020; accepted 20 July 2020
}

\author{
KEYWORDS \\ Energy efficiency \\ programs; \\ Transmission \\ expansion planning; \\ Reactive power \\ planning; \\ Emission reductions; \\ Multi stage planning.
}

\begin{abstract}
Energy efficiency programs as an energy source with multiple advantages (low cost, more reliability, and highly clean) are considered as one of the most effective solutions to meet future energy needs. In this paper, Energy Efficiency Programs (EEPs) are modeled as virtual sources of power generation to investigate their impacts on expanding transmission network and Reactive Power Planning (RPP). A multi-stage model based on $\mathrm{AC}$ power flow is used to indicate the possibility of postponing the investment actions as the investment deferral in Transmission Expansion Planning (TEP). Two groups of regulatory support schemes are considered as investor income to promote participation in EEPs, namely purchasing Certified Emission Reductions (CERs) and shared saving model. In addition, two standard case studies (Garver and 46-bus Brazilian) are evaluated to demonstrate the promising potential of the proposed model in handling the planning problems of practical power systems. The simulation results demonstrate the effectiveness of the proposed model to solve such planning problems in the presence of EEPs.
\end{abstract}

(C) 2022 Sharif University of Technology. All rights reserved.

\section{Introduction}

Energy efficiency policies have been adopted globally to address the public concern about energy supplies, rising energy prices, and the environmental impacts associated with energy usage [1]. Energy Efficiency Programs (EEPs) are one of the least-cost and leading resources available to utilities for reducing energy consumption, saving the primary energy resources, addressing the climate changes, and reducing pollution emitted by burning fossil fuels. Moreover, investing

\footnotetext{
*. Corresponding author.

E-mail addresses: a.1366.m@gmail.com (A.

Mahmoudabadi); mrashidi@uk.ac.ir (M. Rashidinejad); a.abdollahi@uk.ac.ir (A. Abdollahi)
}

doi: $10.24200 /$ sci. 2020.54510 .3784 in EEPs is one-third to half of the cost of generating the same amount of electricity from traditional power sources and can provide significant energy savings to the society, which is also beneficial to the utility side [2]. Therefore, promoting EEPs in electricity usage are essential.

Due to the rapid growth of electric energy consumption, new transmission lines for transferring power from the supply centers to the load centers should be constructed which results in significant investment costs. Energy efficiency and Demand Response programs (DRs) as load management subsets play a vital role to reduce energy consumption and thus reduce environmental pollution, which can be adequately used in power systems planning. DRs change the load profile by shifting the peak-demand times to low-load times, while EEPs reduce the load level and can be more efficient in power system planning than the DRs [3]. 
EEPs have a high potential in postponing investment actions in Transmission Expansion Planning (TEP). The scheduling horizon of the EEPs implementation is usually divided into long-term and mid-term. Since the impact of EEPs on electricity consumption is typically noticeable in later planning horizons, these options are more effective in long-term planning problems such as TEP problems.

In recent years, several types of researches have addressed the integration of EEPs as well as environmental issues in power systems scheduling and planning problems [4-5]. In [6], a model for energy efficiency market was introduced that emphasized the basis for designing more efficient policies in energy efficiency market by examining and developing conventional models. An analytical approach to prioritizing a country's energy efficiency and formulating a practical plan to integrate energy efficiency as a resource for achieving a nation's energy access goals was described in [7]. A two-step approach to investigating the impact of improved energy efficiency on $\mathrm{CO}_{2}$ emission at the macro level was proposed in [8], while an index decomposition analysis was used to obtain real energy efficiency by separating the impact of structural changes in the economic activities on energy intensity. In [9], a new model for simulating the effects of EEPs on the generation expansion planning was introduced, while a method for improving energy efficiency in a distribution system using reactive power sources in [10] was conferred. In [11], a two-stage model was proposed to consider the impacts of DRs and EEPs in a smart grid environment. An overview of the potential of energy efficiency in reducing energy consumption as well as reducing the pollutants emission in the UK industry was presented in [12]. Due to the nonlinear nature and complexity of an optimization problem, various innovative solution methods were studied by researchers [13-15]. A comprehensive review of articles with the applications of heuristic methods to energy efficiency was presented in [16]. In [17], to accommodate the uncertainty and variability of wind power, an innovative scenario-based stochastic model that incorporated generation, transmission, and Reactive Power Planning (RPP) based on relaxed AC optimal power flow was presented; this model sought to balance investment and operation cost while considering the spinning reserve, unit ramp rate, and current output of units. In [18], the impact of the integration of inverterbased distributed energy resources on the protection, control, operation, and planning of power distribution network was investigated. A comprehensive review of recent studies on TEP from restructuring to renewable and distributed electricity markets and their challenges was presented in [19].

The high potential of EEPs in the TEP problems, on the one hand, and the lack of a proper study in joint
TEP and RPP problems simultaneously with EEPs, on the other hand, motivated the authors to provide an in-depth model to investigate the effects of combined EEPs on a joint TEP and RPP problem. The main contributions of this study are listed below:

- To propose an economic model for EEPs based on production function of electric energy consumption. To do so, EEPs are modeled as virtual sources of power generation;

- To introduce two groups of regulatory support schemes as investor income to promote participation in EEPs, namely purchasing Certified Emission Reductions (CERs) and shared saving model;

- To propose a robust mixed-integer model for multistage planning to indicate the possibility of investment deferral;

- To use and extend the AC model for multi-stage planning to assess the loss of real and reactive power to consider voltage constraints.

The rest of this paper is structured as follows. The proposed construction for the EEPs model in the TEP\&RPP problem is investigated in Section 2. The solution methodology as well as solution algorithm principles for the proposed model are described in Section 3; the proposed model is employed on test systems in Section 4. The conclusion is presented in Section 5 .

\section{EEPs associated with TEP\&RPP}

\section{1. $E E P s$}

Energy efficiency can be simply defined as using less energy to produce similar or better products, services, or facilities. Energy efficiency can be implemented by replacing out-of-date appliances, practices, and technologies with new ones that consume less energy [20]. Energy efficiency improvements can be offered at several critical points of an energy system. At homes and offices, it can be considered as tightening building envelopes to prevent wasting the energy used for heating, ventilation and air conditioning, replacing candescent light bulbs with LEDs, swapping out old appliances with new ones, etc. [21]. On the generation side, a power plant can be upgraded to burn less natural gas or coal while still generating the same amount of electricity, if not more. Cars can be designed to go further on a gallon of gases [22]; or, hybrid electric vehicles can use a management system to optimally manage the fuel consumption [23].

Implementation of EEPs in the electricity generation, transmission and consumption sectors can noticeably reduce electricity demand in the grid, which can enhance the reliability of the electricity system. It also saves money and can be more efficient and cost-effective 
than alternative investments to strengthen the power system and production, transmission, and distribution infrastructure. Therefore, energy efficiency can be called as the best medicine to meet the future needs of power system developments. Today, energy efficiency is considered as a great potential in power systems that can reduce greenhouse gas emissions, save money, and create jobs in addition to reducing peak load, and these advantages in response to economic worries and climate change have led lawmakers and regulators to strongly support energy efficiency through financial and technical incentives.

Since 1990, energy efficiency has become the third largest electricity supplier in the United States. Regardless of energy efficiency plans, more than 300 additional large power plants are needed to meet US energy needs. It is anticipated that if energy productivity standards, applications, and energy efficiency codes in buildings reach their full potential, energy efficiency will become the largest US electricity supplier by 2030 and will have many benefits. Figure 1 shows the share of each US power generation resource in 2030 with the increased energy efficiency policies [24].

Energy efficiency can also perform the same function of transmission and distribution sources in power systems and reduce power through transmission lines and equipment. These reductions can delay the need for upgrading traditional network infrastructure or even prevent new equipment from being installed. Hence, in this paper, the significant impacts of energy efficiency on transmission network development planning are examined.

Energy efficiency improvements decrease fossil fuel consumption and thereby mitigate emissions, thus promoting social welfare and substantial health benefits [25]. Industrial EEPs can provide significant

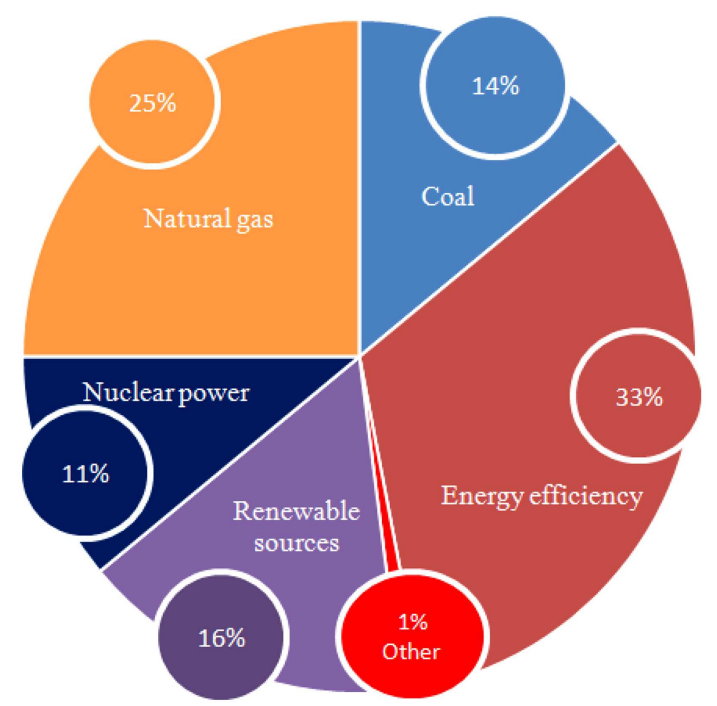

Figure 1. Share of US electricity generation by resource in 2030 . energy savings for society, and the utility system at a lower cost than most programs is targeted at other sectors [26]. The amount of electricity saved by industrial programs directly displaces the requirement to invest in expensive power plants or transmission and distribution system upgrades. The surcharges due to the investment in these assets will be customers' responsibility and the electricity bills are kept high; therefore, lack of investment or postponement of the investment is a remedy to prevent increasing the bills [27].

\subsection{EEPs model}

In this paper, the introduction of a comprehensive model of EEPs associated with TEP\&RPP is considered as one of the important issues. Therefore, this section presents a comprehensive mathematical formulation of the EEPs and TEP\&RPP model. Virtual power plants are considered as the EEPs due to their effectiveness. These power plants are installed at load centers and participate in providing electricity according to their characteristics.

In order to model the effects of energy efficiency investment costs on the demand side, a production function is used for electricity consumption as the EEP supply curve [9]. The proposed model of electricity consumption in the presence of EEPs depends on the price elasticity of electricity consumption and the elasticity of electricity consumption by considering EEP investment (EEI). It is worth mentioning that for the sake of simplicity, only the self-elasticity of electricity consumption concerning the energy efficiency investment is taken into account and other elasticities are neglected. This function is given as follows:

$$
E_{t}=D\left(E E I_{t}\right)
$$

The EEPs are assumed to be divided into $\mathrm{k}$ types in terms of profit/cost ratio. The electricity consumption function in the presence of EEPs can be approximately linearized at $k$ points by a Taylor series, while for the sake of simplicity, the second and higher orders of the partial derivatives are ignored. This function is linearized as follows:

$$
\begin{aligned}
D\left(E E I_{t}\right)= & D\left(E E I_{0 i}\right)+\frac{\partial D\left(E E I_{0 i}\right)}{\partial E E I_{t}} \\
& \times\left(E E I_{t}-E E I_{0 i}\right) ; \quad \mathrm{i}=1, \ldots, d .
\end{aligned}
$$

The difference in power consumption after the presence of EEPs indicates the amount of power savings as follows:

$$
E S_{i, t}=D\left(E E I_{t}\right)-D\left(E E I_{0 i}\right) .
$$

The electricity consumption sensitivity with respect to the investment of EEPs is defined as energy efficiency elasticity, which is expressed in the following equation: 


$$
\delta_{i, t}=\frac{\partial D\left(E E I_{0 i}\right)}{\partial E E I_{t}}
$$

It should be noted that electricity consumption elasticity with energy efficiency investment, $\delta_{i, t}$, is negative because of the positive role of EEPs in reducing the consumption and also, the results may vary in the case of each EEP. By inserting Eqs. (2) and (4) into Eq. (3), Eq. (5) is obtained:

$$
E S_{i, t}=\delta_{i, t} \times\left(E E I_{t}-E E I_{0 i}\right)
$$

The real assumption is that the priority of using EEPs is done based on the lowest investment cost. Therefore, the cumulative saving of electricity can be achieved by collecting the amount of power savings from the implementation of previous EEPs as follows:

$$
C E S_{i, t}=\sum_{m=1}^{i-1} E S_{m, t}^{\max }-E S_{i, t}
$$

By substituting Eq. (5) into Eq. (6), Eq. (7) is obtained:

$$
C E S_{i, t}=\sum_{m=1}^{i-1} E S_{m, t}^{\max }-\delta_{i, t} \times\left(E E I_{t}-E E I_{0 i}\right) .
$$

The cumulative saving of electricity due to investment in EEPs is illustrated by this equation. The energy efficiency investment function is obtained by presenting Eq. (7) as Eq. (8).

$$
E E I_{t}=1 / \delta_{i, t}\left(\sum_{m=1}^{i-1} E S_{m, t}^{\max }-C E S_{i, t}\right)+E E I_{0 i}
$$

The total investment curve of EEPs is shown in Figure 2 as the investment function of cumulative electricity saving for all EEPs. Each section of this curve refers to a specific type of EEPs, e.g., the section

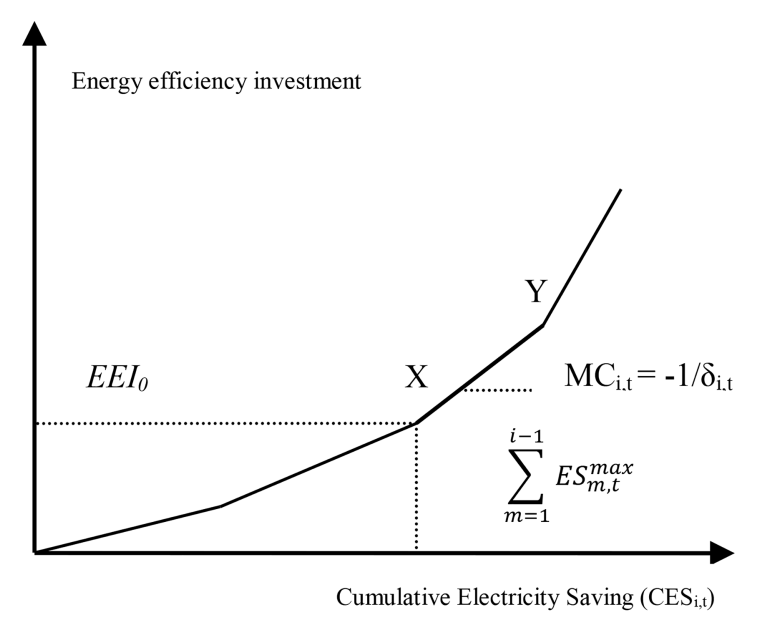

Figure 2. Total investment curve of Energy Efficiency Programs (EEPs). between points $\mathrm{X}$ and $\mathrm{Y}$ stands for the cost-saving function for the $i$ th type of EEP. From this curve, the marginal cost of energy savings for EEPs is obtained as Eq. (9):

$$
M C_{i, t}=-1 / \delta_{i, t} .
$$

In this section, it is assumed that there are enough economic incentives to encourage investors to participate in EEPs. If the incentive is lower than a sufficient value, the investor will have no incentive to invest in these resources. Multifarious incentive-based support schemes have been designed to increase the penetration rate of the EEPs in the electricity system. Moreover, two groups of regulatory support schemes are considered as the income of EEP investors for promoting participation in EEPs, namely purchasing CERs and shared saving model.

CERs are a type of emissions unit (or carbon credits) issued by the Clean Development Mechanism (CDM) executive board for emission reductions achieved by CDM projects and verified by a Designated Operational Entity (DOE) under the rules of the Protocol. Purchasing CERs can be one of the income sources for investors in EEPs [28]. This function is given as follows:

$$
f^{C E R}=\sum_{t \in T} \lambda^{C E R} \sum_{i=1}^{k}\left(E M F_{C O 2}\right) \times C E S_{i, t},
$$

where $\lambda^{C E R}$ is the CER price (\$/ton), $E M F_{C O 2}$ the amount of carbon dioxide reduction due to reduced energy consumption (ton/MWh), and $f^{C E R}$ the function of purchasing CER from EEPs. Moreover, a shared saving model is used to promote investors' incentive to participate in EEPs.

Energy Service Companies (ESCOs) develop, design, build, and fund EEPs that save energy, reduce energy costs, and decrease operations and maintenance costs at customers' facilities. In general, ESCOs act as project developers for a comprehensive range of energy conservation measures and take into account the technical and performance risks associated with a project [29]. In this case, ESCOs invest in energy efficiency projects and based on a predetermined percentage for several years, the cost savings are shared with consumers [30]. The following function is used as follows:

$$
f^{S S C}=\sum_{t \in T} S S C \times E E I_{t},
$$

where $S S C$ is the sharing coefficient and $f^{S S C}$ is the sharing function. The objective function of EEPs can be obtained as follows:

$$
f^{E E P}\left(P^{E E P}, u_{e}\right)=\sum_{t \in T} E E I_{t}-f^{C E R}-f^{S S C} .
$$

This objective function is employed to find the 
best set of solutions for EEPs model. The binary variable $u_{e}$ shows the connection between the virtual power plant and a demand bus or their disconnection; $P^{E E P}$ is the amount of power that the EEPs can reduce in a given period and can be obtained using Eq. (13):

$$
P^{E E P}=\sum_{t \in T} C E S_{i, t} .
$$

\subsection{Multi-stage TEP\&RPP model}

Generally, there are two types of TEP problems, namely static and dynamic. The static TEP problem is the simplest model that considers the whole planning horizon in one stage, and the lines that can be optimally used to reinforce the network are determined out of the candidate lines in one stage only. Investment is made at the beginning of the planning horizon. The dynamic or multiple-year planning approaches define not only the optimal locations and types of the equipment but also the most appropriate times for making such investment. In the dynamic TEP problem, it is required to consider multi-time periods as well as possible transmission reinforcements at each time. Investments are carried out at the beginning of each stage. In multi-stage TEP problems, the objective function is the minimization of the present value of the investment decisions made throughout the horizon.

From the mathematical perspective, multi-stage TEP problems are mixed-integer non-linear problems and consequently, the problem is very complicated since the development timeline should be considered besides the number of circuits that must be added to the system. Upon increasing the number of variables and constraints, the planning problem requires much computational effort. Some useful examples of multistage models were addressed in [31-34]. In this work, an AC model for multi-stage TEP is used to assess the loss of real and reactive power accurately. This model is able to provide the most economical TEP based on the scheduling development of power grids. In this model, one year is considered as the base year that TEP begins with. Concerning the annual interest rate $I$, the current value of investment costs for the base year $t_{0}$ with the horizon of steps $T$ is as follows:

$$
\begin{aligned}
c(x)= & c_{1}(x)+(1-I)^{t_{1}-t_{0}} c_{2}(x)+\ldots \\
& +(1-I)^{t_{T-1}-t_{0}} c_{T}(x)=\sum_{i=1}^{T}(1-I)^{t_{i-1}-t_{0}} c_{i}(x) \\
& =\sum_{i=1}^{T} \delta_{i n v}^{i} c_{i}(x)
\end{aligned}
$$

In Eq. (14), all the financial terms are converted by an appropriate term to take into account the time value of financial investments, where $\delta_{i n v}^{i}$ is the factor used to calculate the present investment value at stage $t$ as follows:

$$
\delta_{i n v}^{i}=(1-I)^{t_{i-1}-t_{0}} .
$$

The mathematical model for multi-stage TEP and RPP problem can be formulated as follows:

- Objective function: The objective function of this problem is to minimize the total cost of the system, including development planning costs as well as the investment on reactive power resources in a given planning horizon. The objective function can be calculated using Eq. (16):

$$
v_{1}=\sum_{t=1}^{T} \delta_{i n v}^{t}\left[\sum_{(i, j)} c_{i j} \cdot n_{i j}^{t}+f\left(Q_{G}^{t}, u_{q}\right)\right] .
$$

The first term of Eq. (16) stands for the investment costs of transmission lines, and the second term represents the investment costs of reactive power resources. In the present work, to avoid the complexity of the model, the optimal planning of Var sources is done with shunt capacitors, assuming that these equipment pieces are installed at high voltages and a portion of the reactive power consumption of the network is provided by them. The investment cost of reactive resources is presented as follows:

$$
f\left(Q_{G}^{t}, u_{q}\right)=\sum_{k \in \boldsymbol{\Omega}_{d}}\left(c_{0 d}+c_{1 d} Q_{G d}^{t}\right) u_{d} .
$$

- Equality constraint: Active and reactive power should be adequately generated to satisfy the corresponding demands via Eqs. (18) and (19), respectively:

$$
\begin{aligned}
& P(V, \theta, n)-P_{G}+P_{D}=0, \\
& Q(V, \theta, n)-Q_{G}-Q_{G_{0}}+Q_{D}=0,
\end{aligned}
$$

where $n$ is the number of circuits (lines and transformers).

- Inequality constraints: The TEP\&RPP problem is subject to several inequality constraints during the planning horizon [35] as Eqs. (20)-(26). The active and reactive generation is bound within the lower and upper limits.

$$
\begin{aligned}
& \underline{P}_{G} \leq P_{G} \leq \overline{P_{G}}, \\
& \underline{Q}_{G} \leq Q_{G} \leq \overline{Q_{G}}, \\
& \underline{Q}_{G}^{\mathbf{0}} \leq Q_{G}^{\mathbf{0}} \leq \bar{Q}_{G}^{\mathbf{o}}, \\
& \underline{V} \leq V \leq \bar{V}, \\
& \left(N+N^{0}\right) S^{\text {from }} \leq\left(N+N^{0}\right) \bar{S},
\end{aligned}
$$




$$
\begin{aligned}
& \left(N+N^{0}\right) S^{\text {to }} \leq\left(N+N^{0}\right) \bar{S} \\
& 0 \leq n \leq \bar{n} .
\end{aligned}
$$

Eq. (20) stands for the upper and lower limits of active power generation, while Eqs. (21) and (22) show the reactive power limitations of the new and existing sources, respectively; the voltage level is limited by Eq. (23); transmission line MVA limits are enforced by Eq. (24) and Eq. (25) for sending and receiving points, respectively; and Eq. (26) shows the maximum number of candidate lines to be installed. The elements of vectors $P$ and $Q$ are represented by Eqs. (27) and (28), respectively:

$$
\begin{aligned}
P_{i}(V, \theta, n)= & V_{i} \sum_{j \in N_{B}} V_{j}\left[G_{i j}(n) \cos \theta_{i j}\right. \\
& \left.+B_{i j}(n) \sin \theta_{i j}\right], \\
Q_{i}(V, \theta, n)= & V_{i} \sum_{j \in N_{B}} V_{j}\left[G_{i j}(n) \sin \theta_{i j}\right. \\
& \left.-B_{i j}(n) \cos \theta_{i j}\right],
\end{aligned}
$$

where the admittance matrix elements $G$ and $B$ are represented by Eqs. (29) and (30), respectively:

$$
\begin{gathered}
G=\left\{\begin{array}{c}
G_{i j}(n)=-\left(n_{i j} g_{i j}+n_{i j}^{0} g_{i j}^{0}\right) \\
G_{i i}(n)=\sum_{j \in \Omega_{d}}\left(n_{i j} g_{i j}+n_{i j}^{0} g_{i j}^{0}\right)
\end{array}\right\}, \\
B=\left\{\begin{array}{c}
B_{i j}(n)=-\left(n_{i j} b_{i j}+n_{i j}^{0} b_{i j}^{0}\right) \\
B_{i i}(n)=b_{i}^{s h}+\sum_{j \in \Omega_{l}}\left[n_{i j}\left(b_{i j}+b_{i j}^{s h}\right)\right. \\
\left.+n_{i j}^{0}\left(b_{i j}^{0}+\left(b_{i j}^{s h}\right)^{0}\right)\right]
\end{array}\right\} .
\end{gathered}
$$

The elements $i j$ of vectors $S^{\text {from }}$ and $S^{\text {to }}$ as well as the required definitions are given by Eqs. (31)-(36):

$$
\begin{aligned}
& S_{i j}^{\text {from }}=\sqrt{\left(P_{i j}^{\text {from }}\right)^{2}+\left(Q_{i j}^{\text {from }}\right)^{2}} \\
& P_{i j}^{\text {from }}=V_{i}^{2} g_{i j}-V_{i} V_{j}\left(g_{i j} \cos \theta_{i j}+b_{i j} \sin \theta_{i j}\right) \\
& Q_{i j}^{\text {from }}=-V_{i}^{2}\left(b_{i j}^{s h}+b_{i j}\right)-V_{i} V_{j}\left(g_{i j} \sin \theta_{i j}\right. \\
& \left.\quad-b_{i j} \cos \theta_{i j}\right), \\
& S_{i j}^{t o}=\sqrt{\left(P_{i j}^{t o}\right)^{2}+\left(Q_{i j}^{t o}\right)^{2}}, \\
& P_{i j}^{t o}=V_{j}^{2} g_{i j}-V_{i} V_{j}\left(g_{i j} \cos \theta_{i j}-b_{i j} \sin \theta_{i j}\right), \\
& Q_{i j}^{t o}=-V_{j}^{2}\left(b_{i j}^{s h}+b_{i j}\right)+V_{i} V_{j}\left(g_{i j} \sin \theta_{i j}+b_{i j} \cos \theta_{i j}\right) .
\end{aligned}
$$

\section{Solution methodology}

In this paper, due to the complexity of the proposed multi-stage joint TEP and RPP in the presence of EEPs, a heuristic-based approach is used. The heuristic approach determines the required number of lines to be installed, Var compensators, and EEPs, while several iterations are conducted to obtain a high-quality solution that satisfies all the operational constraints.

\subsection{Solving process}

The overall procedure for solving TEP\&RPP associated with EEPs is as follows.

1. An initial set of solution is generated where each individual solution is randomly chosen.

2. At this stage, each solution is checked for cost. Those individual solutions whose investment costs are very high will be cut off.

3. The information of each individual solution is read out and the new network based on this information is constructed. This information includes the number and location of new lines and the location and size of VAr resources as well as features of EEP.

4. In this section, the TEP problem is formulated based on the AC OPF equations [35] and is solved for each individual solution according to the following objectives:

$$
\begin{aligned}
& \min v=\sum_{i=1}^{n}\left(f_{1 i}\left(P_{G i}\right)+f_{2}\left(Q_{G i}\right)\right) \\
& +f^{E E P}\left(P^{E E P}, u_{e}\right)+v_{1}, \\
& P(V, \theta)-P_{G}+P_{D}-P^{E P P}=0, \\
& Q(V, \theta)-Q_{G}-q+Q_{D}=0, \\
& \underline{P}_{G} \leq P_{G} \leq \bar{P}_{G}, \\
& \underline{Q}_{G} \leq Q_{G} \leq \bar{Q}_{G}, \\
& \underline{q} \leq q \leq \bar{q}, \\
& \underline{P}^{E P P} \leq P^{E P P} \leq \bar{P}^{E P P}, \\
& S^{\text {from }} \leq \bar{S} \\
& S^{\text {from }} \leq \bar{S} \\
& S^{t o} \leq \bar{S}
\end{aligned}
$$

where $v_{1}$ is the total investment cost of the system, including the costs of network expansion planning as well as the financial burden of reactive resources 
over a given horizon; $f_{1 i}$ and $f_{2 i}$ denote the costs of active and reactive power generation by the generator $i$, respectively.

5. The fitness function for all individuals is calculated according to the results obtained in the previous step.

6. When the OPF problem is solved for the entire individual solutions and the values are calculated, the selection, recombination, and mutation are carried out and a new set of the individual solutions is generated. When all the individual solutions are the same, there is no new individual and the process can be stopped, while another stopping criterion is the number of generations.

7. According to the measures introduced to stop the algorithm and the convergence of the approach, the trends will be stopped or continued by going back to the second stage.

\subsection{Solution algorithm}

Generally, heuristic-based algorithms can be considered as a method for solving both constrained and unconstrained optimization problems that are based on natural selection, the process that drives a biological evolution. It is frequently used to find optimal or near-optimal solutions among many locally optimal solutions. The heuristic-based algorithm consists of maintaining a population of individuals that represent potential solutions to the problem to be solved, that is, the optimization of a function is generally very complex. This algorithm repeatedly modifies a set of individual solutions. At each step, the algorithm selects individuals at random from the current population to be parents and uses them to produce new solutions for the next generation. Over successive generations, the population "evolves" toward an optimal solution. Based on these evaluations, a new population is formed using a mechanism of selection and applying operators such as crossover and mutation. Encoding, selection, recombination, mutation, and fitness evaluation are the main stages of the proposed algorithm. Problem codification and fitness evaluation as the most important stages of heuristic-based algorithm are discussed in detail in the following section.

\subsection{Problem codification}

One of the most important parts of the heuristic-based algorithms is the problem codification, which matters more in solving complex problems. Each individual introduces a developed network that includes added lines, reactive power sources installed on demand buses and EEPs.

Codification is a very important issue when a heuristic-based algorithm is designed in dealing with a combinatorial problem. A proper codification may prevent complexity of the implementation of the solution algorithm. The individual is a solution proposal for the planning problem; or, in better terms, it is a topology made up of all transmission lines, VAr sources, and EEPs characteristics added to the system corresponding to their investment proposal. In the TEP\&RPP associated with EEPs, the individual of the solution algorithm is represented by a group of vectors. The range of variations of each member for the part related to the transmission lines is determined according to the limitations given by Eq. (26). The limitations given by Eqs. (42) and (43) determine the range of members for the components of reactive power sources and EEPs (the capacity of the virtual power plant), respectively. Each member of this vector may vary from zero to the maximum value of the corresponding variables. Thus, a simple codification is shown in Figure 3.

\subsection{Fitness evaluation}

The fitness of an individual in a heuristic-based algorithm is the value of an objective function. For calculating fitness, the possible solution should be decoded first and the objective function must be evaluated. Finally, the algorithm must evaluate the fitness level of the new solutions in order to select the following candidates whose members will be recombined. It is worth mentioning that the fitness not only indicates how good the solution is but also corresponds to how

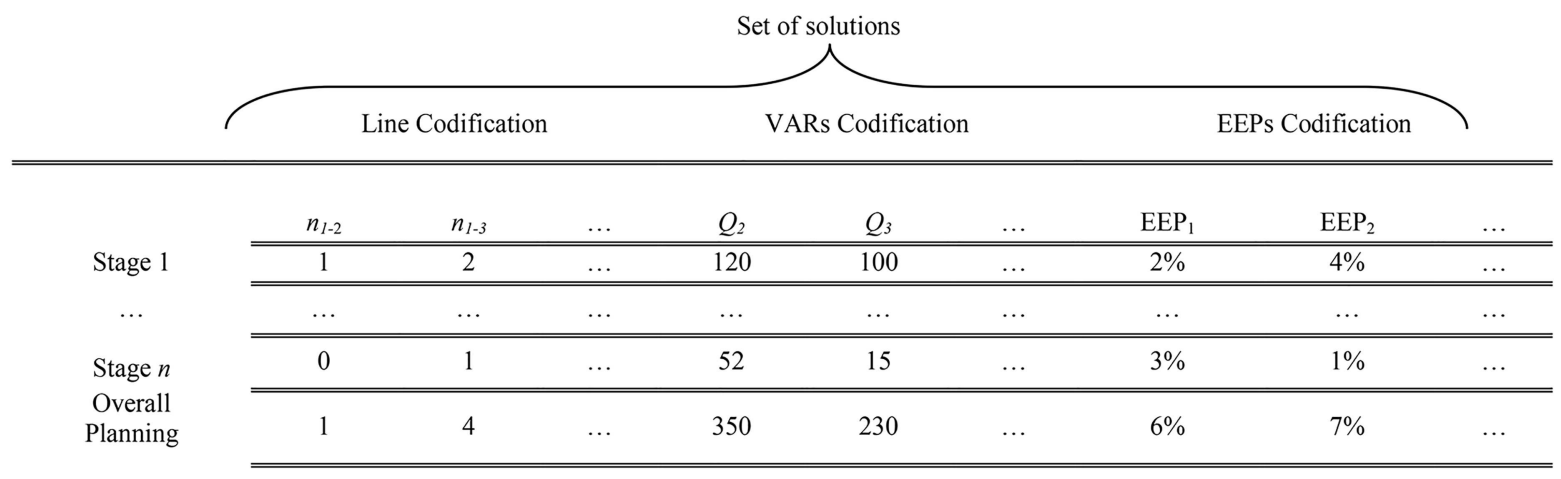

Figure 3. Simple codification. 
close the set of solutions is to the optimal one. The objective function provided in this article is to seek to achieve the following objectives:

1. Deviation from the limitation of constraints;

2. Cost of TEP;

3. Cost of RPP; and

4. Investment in EEPs.

The objective function can be used in the following equation:

objective function $=w_{1}\left(v_{1}\right)+w_{2}\left(v_{2}\right)+w_{3}\left(v_{3}\right)$

$$
+w_{4}\left(d_{V}\right)+w_{5}\left(d_{G}\right)+w_{6}\left(d_{S}\right)
$$

where $v_{1}$ is the cost of TEP, $v_{2}$ the cost of RPP, $v_{3}$ the investment of EEPs, $d_{V}$ the sum of deviations from voltage limitations, $d_{G}$ the sum of deviations from power generation limitations, and $d_{S}$ the sum of deviations from power flow limitation of branches.

Moreover, $w_{1}-w_{6}$ are the weight coefficients that can be selected by the decision-maker; these coefficients must be selected in such a way as to satisfy the following equation:

$$
\sum_{i=1}^{6} w_{i}=1
$$

\section{Illustrative tests}

For the illustrative test, two systems are studied, namely a well-known Garver system and the practical south Brazilian 46-bus system. The main objectives of the tests are to demonstrate the effectiveness of the presented multi-stage TEP\&RPP model along with EEPs in reducing the investment costs and mitigating the greenhouse gas comparison with other planning models. In this study, the EEPs cost curve and EEPs marginal cost are derived from historical data of Iran Energy Efficiency Organization (IEEO) [9], as shown in Table 1. The historical data include the Cumulative Energy Saving (CES) and its corresponding cost. In this table, EEPs are divided into three levels including low, medium, and high costs. The energy savings and marginal costs associated with each group of EEPs are ranked in the second and third columns, respectively. The proposed algorithm is implemented in a programming-based language, AMPL [36]. The AMPL code is run on a computer with Intel core ${ }^{\mathrm{TM}}$ i7 processor clocking at $2.5 \mathrm{GHz}$ RAM and with installed memory of $8.00 \mathrm{~GB}$.

\subsection{Garver system}

To indicate the potential of EEPs in TEP problems, the model is investigated via a well-known example namely the Garver system that considers a small electricity system. This system has six buses and fifteen branch candidates; the total demand is $760 \mathrm{MW}$; $152 \mathrm{MVAr}$ and a maximum of 5 lines can be added to each branch, where the Garver system data were given in [9]. Six different tests were implemented, while three different cases were used:

Case 1. TEP without reactive planning;

Table 1. The marginal cost of energy efficiency programs (EEPs).

\begin{tabular}{ccc}
\hline Classification & $\begin{array}{c}\text { Cumulative energy } \\
\text { saving (\%) }\end{array}$ & $\begin{array}{c}\text { The marginal cost of } \\
\text { EEPs }(\$ \mathbf{M W h})\end{array}$ \\
\hline \multirow{2}{*}{ Low cost EEPs } & 0.4 & 6 \\
& 0.8 & 7.7 \\
& 1 & 9.8 \\
& 1.2 & 12.6 \\
& 1.4 & 16.1 \\
Medium cost EEPs & 1.6 & 20.6 \\
& 1.8 & 26.4 \\
& 2 & 30.7 \\
& 2.2 & 43.19 \\
& & 55.2 \\
High cost EEPs & 2.4 & 70.7 \\
& 2.6 & 90.3 \\
& 2.8 & 115.5 \\
& 3.0 & 147.5 \\
\hline
\end{tabular}


Case 2. TEP\&RPP without considering EEPs;

Case 3. TEP\&RPP with considering EEPs.

For each case, two tests are managed: single-stage planning and multi-stage planning.

The assumptions of the problem are as follows:

- The annual interest value $I=10 \%$;

- The VAr-plant fixed costs $c_{0}=10000 \$$;

- The VAr-plant variable costs $c_{1}=30 \$ / \mathrm{kVAr}$;

- The shared saving model $=50 \%$ for ten years;

- The emission factor $=0.735$ ton $/ \mathrm{MWh}$; and

- The CER price is assumed to be $15 \$$.

\section{Test 1: Single-stage TEP}

In this test, a single-stage TEP was implemented on the Garver system. The planning process resulted in the line investment of $\$ 160$ million and the following lines are added:

$$
n_{2-6}=2, \quad n_{3-5}=2, \quad n 4-6=2 .
$$

Active power loss is $11.68 \mathrm{MW}$. Figure 4 shows the complete results of Test 1. In Figure 4, the lines added to the base system are shown as dashed lines and the line loading rate is also expressed as percentage, e.g., the line loading between buses 2 and 3 is about $72.9 \%$. According to Figure 4, all constraints related to power flow such as bus voltage constraints, generator power limitations, and transmission line power are fully respected.

Test 2: Single-stage TEP\&RPP

In this test, this study implements single-stage TEP

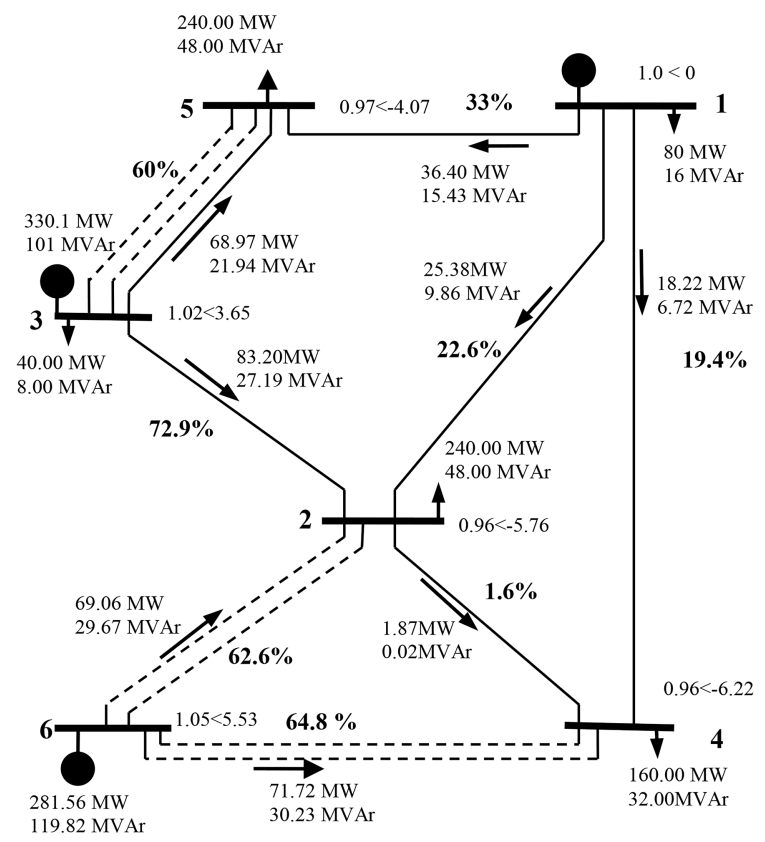

Figure 4. Planning result of Test 1.

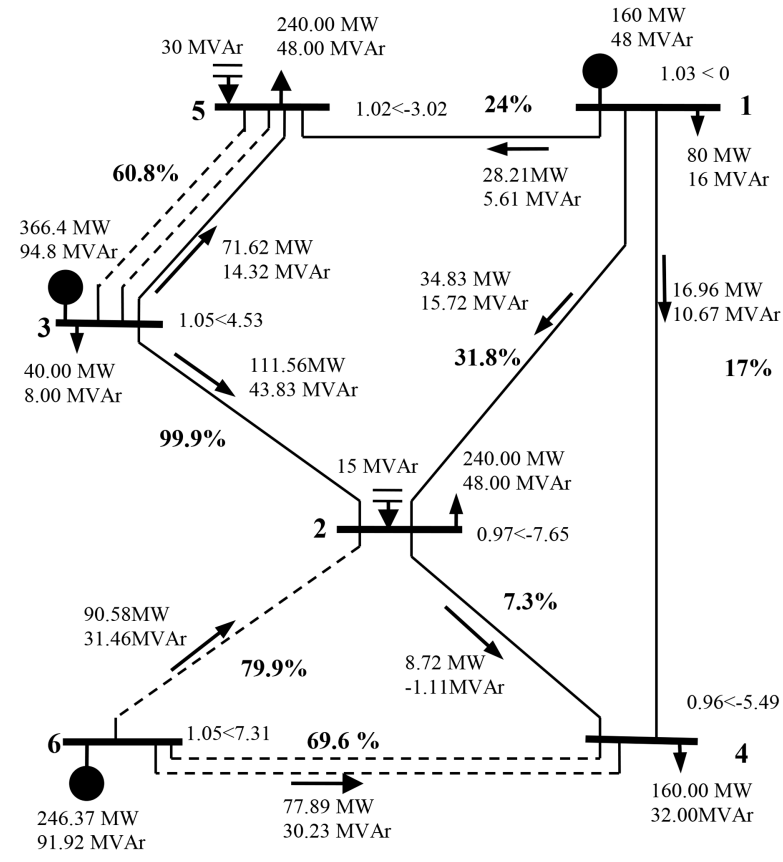

Figure 5. Planning result of Test 2.

and RPP simultaneously on the Garver system. The planning process results in a line investment of $\$ 130$ million and the following lines are added:

$$
n_{2-6}=1, \quad n_{3-5}=2, \quad \text { and } \quad n_{4-6}=2 .
$$

Active power loss is $12.77 \mathrm{MW}$ and the total $45 \mathrm{MVAr}$ reactive power source must be installed at buses 2 and 5 . Figure 5 shows the result of this test. Figure 5 shows the lines added to the base system as dashed lines, compared to Test 1; simultaneous problem solving for transmission line development and reactive resources has prevented the construction of a single line between buses 2 and 6 and the cost of developing the transmission network has been reduced by $\$ 28.63$ million. In this test, reactive power is provided locally at buses 2 and 5 ; thus, the capacity of the transmission lines is released substantially.

\section{Test 3: Single-stage TEP\&RPP in the presence of $\mathrm{EEPs}$}

In this test, it is assumed that EEPs have been applied to the Garver system. The planning process resulted in line investment of $\$ 110$ million and the following lines are added:

$$
n_{2-6}=1, \quad n_{3-5}=1, \quad n_{4-6}=2 .
$$

Active power loss is $14.81 \mathrm{MW}$. The capacities of reactive power compensators at buses 2 and 5 are 16 and 25 MVAr, respectively. In this system, EEPs have been implemented on buses 2, 4, and 5 and these programs have reduced the consumption of each bus by $1.2,1.6$, and 1.8 percent, respectively. Figure 6 shows 


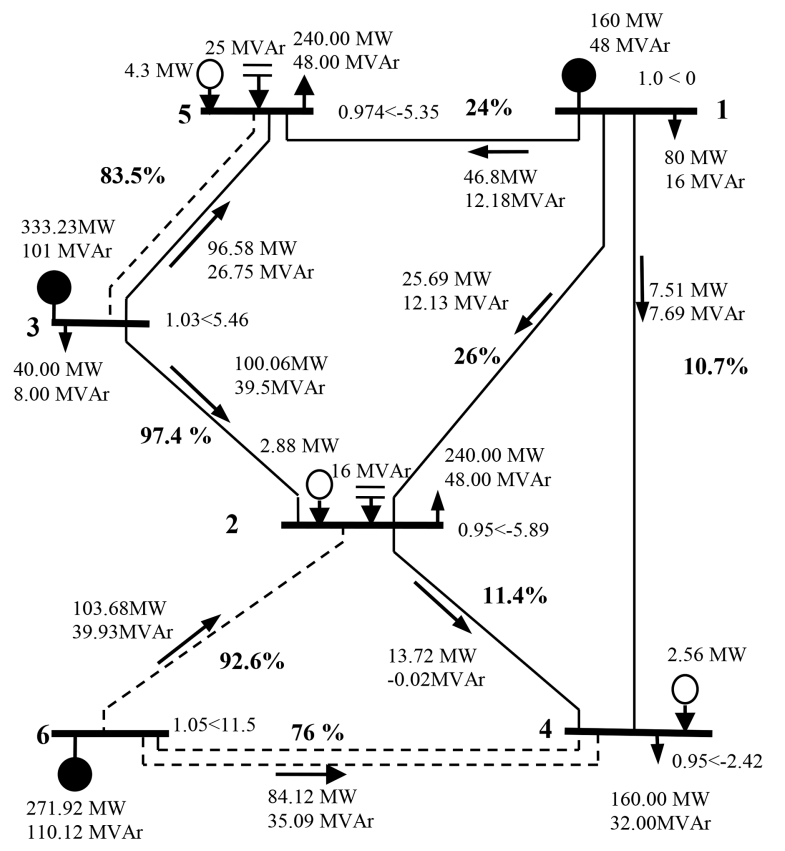

Figure 6. Planning result of Test 3 .

the complete test results. Compared with the results of Test 2, the implementation of EEPs avoids building a line between buses 2 and 6 and also, the cost of the transmission lines planning is reduced by $\$ 20$ million. Table 2 summarizes the results of Tests 1 to 3 . Columns $2-4$ show the planning results of each test and columns 5-7 show the cost of each program. As can be seen from the results, the investment cost has been reduced due to the application of energy efficiency plans and the pollution caused by carbon dioxide gas has decreased by more than 180 million $\mathrm{kg}$.

\section{Test 4: Mutli-stage TEP}

The test runs a multi-stage TEP on the Garver system. In this case, the three 5-year stages of $P 1, P 2$, and
$P 3$ are considered as the planning stages. Stage $P 1$ is the period ranging from 2020 to 2025 where 2020 is considered as the base year for this stage. In the $P 2$ stage, 2025 is the base year with duration of 5 years from 2025 to 2030 . The last planning stage is $P 3$, starting from 2030 to 2035 . It should be noted that all investments should be discounted to the base year 2020. The following lines are added for the first stage P1 (2020-2025):

$$
n_{2-6}=1, \quad n_{3-5}=2, \quad n_{4-6}=1 .
$$

In the second stage $P 2$ (2025-2030), one branch must be installed between buses 4 and 6 ; in the last stage $P 3$ (2030-2035), one line is added in $n_{2-6}=1$ route. In this case, the investment cost of lines is about M\$US128.4. However, in Test 1, for a single-stage planning model, the investment cost of lines was about M $\$$ US160, showing $20 \%$ higher costs. Given that multistage investment planning is carried out at different intervals, the final investment cost will be noticeably reduced by considering a $10 \%$ interest rate.

\section{Test 5: Multi-stage TEP\&RPP}

In this test, a multi-stage mode with RPP is implemented on the Garver system. The planning horizons of this test are similar to those in Test 4 . The following lines are added for the first stage $P 1$ (2020-2025):

$$
n_{2-6}=1, \quad n_{3-5}=2, \quad n_{4-6}=1 .
$$

According to the simulation results, the system does not need reactive power sources in this stage. In the second time horizon P2 (2025-2030), there is no need to add new transmission lines to the grid and only reactive power resources must be added to the network as in the following: $Q_{2}=5 \mathrm{MVAr}, Q_{5}=25 \mathrm{MVAr}$. In the last stage $P 3$ (2030-2035), one line must be added in $n_{4-6}=1$ route. In this case, the investment cost of

\begin{tabular}{|c|c|c|c|c|c|c|c|c|}
\hline Tests & $\begin{array}{c}\text { TEP } \\
\text { results }\end{array}$ & $\begin{array}{c}\text { RPP } \\
\text { results } \\
\text { (MVAr) }\end{array}$ & $\begin{array}{c}\text { EEP } \\
\text { results }\end{array}$ & $\begin{array}{c}\text { Line } \\
\text { investment } \\
(\mathrm{M} \$)\end{array}$ & $\begin{array}{c}\text { VAr } \\
\text { investment } \\
(\mathrm{M} \$)\end{array}$ & $\begin{array}{c}\text { EEP } \\
\text { investment } \\
(\mathrm{M} \$)\end{array}$ & $\begin{array}{c}\text { Total } \\
\text { investment } \\
(\mathrm{M} \$)\end{array}$ & $\begin{array}{c}\mathrm{Co}_{2} \text { Emission } \\
\text { Reduction } \\
\left(10^{6} \mathrm{~kg}\right)\end{array}$ \\
\hline $\begin{array}{l}\text { Test 1: } \\
\text { TEP }\end{array}$ & $\begin{array}{l}n_{2-6}=2 \\
n_{3-5}=2 \\
n_{4-6}=2\end{array}$ & - & - & 160 & - & - & 160 & - \\
\hline $\begin{array}{c}\text { Test } 2: \\
\text { TEP\&RPP }\end{array}$ & $\begin{array}{l}n_{2-6}=1 \\
n_{3-5}=2 \\
n_{4-6}=2\end{array}$ & $\begin{array}{l}Q_{2}=15 \\
Q_{5}=30\end{array}$ & - & 130 & 1.37 & - & 131.37 & - \\
\hline $\begin{array}{c}\text { Test } 3: \\
\text { TEP\&RPP EEP }\end{array}$ & $\begin{array}{l}n_{2-6}=1 \\
n_{3-5}=1 \\
n_{4-6}=2\end{array}$ & $\begin{array}{l}Q_{2}=16 \\
Q_{5}=25\end{array}$ & $\begin{array}{l}\mathrm{EEP}_{2}=1.4 \% \\
\mathrm{EEP}_{4}=1.6 \% \\
\mathrm{EEP}_{5}=1.8 \%\end{array}$ & 110 & 1.25 & 16.17 & 127.42 & 180.5 \\
\hline
\end{tabular}

Table 2. Results of single-stage planning-Garver system. 
TEP\&RPP is about M $\$$ US110.9. However, in Test 2, for a single-stage planning model, the investment cost of planning was about M $\$$ US130, thus demonstrating that the cost of investment was reduced by M $\$$ US 19.1.

\section{Test 6: Multi-stage TEP\&RPP in the presence of EEPs}

In this test, a multi-stage TEP with RPP is implemented on the Garver system. In this test, it is assumed that EEPs were implemented on the Garver system. The planning horizons of this test are similar to those mentioned in Test 4 . Table 3 shows the complete results of Test 6 . In this case, the investment costs of TEP\&RPP in the presence of EEPs are about M $\$$ US99.63. However, in Test 3, for a singlestage planning model, the investment costs of planning were about M MS127.42, showing that the cost of investment decreased by M $\$$ US27.8.

\subsection{6-bus system (southern Brazilian network)}

The southern Brazilian 46-bus system is employed to show the effectiveness of the proposed model in dealing with practical cases. The single-mode diagram of the 46-bus system was presented in [37]. The system consists of 46 buses and 79 circuits, while the active and reactive demands for the entire planning horizon are $6880 \mathrm{MW}$ and $1032 \mathrm{MVAr}$ [35], respectively. The maximum number of parallel transmission lines that can be added between two buses is limited to four. In this case, the four stages of $P 1, P 2, P 3$, and $P 4$ are considered. The period of stage $P 1$ ranges from 2020 to 2025 where 2020 is considered as the base year. In the $P 2$ stage, 2025 is the base year with a duration of 5 years from 2025 to 2030 . The 3rd stage is $P 3$, with a duration of 2030 to 2035 where 2030 is considered as the base year. The last planning stage is P4 with the duration from the year 2035 to 2040 and the base year is 2035. The annual interest rate value is set to $10 \%$. The details of results derived through the implementation of TEP\&RPP along with EEPs for this system are given in Table 4. In Table 4, the first column outlines the planning time periods; the second column presents the results of the TEP and the lines added for the network reinforcement. The RPP results are shown in the third column of the table; this column shows the amount of reactive power installed on each bus. The percentages of participation in EEPs are outlined in the next column. The last column of

Table 3. Expansion results of Test 6 - Garver system.

\begin{tabular}{cccc}
\hline The stages of planning & TEP results & RPP results (MVAr) & EEP results (\%) \\
\hline$P 1(2020-2025)$ & $n_{3-5}=1$ & - & $\mathrm{EEP}_{2}=1.4, \mathrm{EEP}_{4}=1.6, \mathrm{EEP}_{5}=1.6$ \\
& $n_{4-6}=2$ & $Q_{3}=11$ & $\mathrm{EEP}_{2}=1, \mathrm{EEP}_{4}=1.4, \mathrm{EEP}_{5}=1.8$ \\
& - & $Q_{5}=15$ & \\
& & $Q_{3}=15$ & $\mathrm{EEP}_{2}=1.4, \mathrm{EEP}_{4}=1.2, \mathrm{EEP}_{5}=1.8$ \\
\hline
\end{tabular}

Table 4. Expansion results of 46-bus system.

\begin{tabular}{|c|c|c|c|c|}
\hline $\begin{array}{l}\text { The stages } \\
\text { of planning }\end{array}$ & $\begin{array}{l}\text { TEP } \\
\text { results }\end{array}$ & $\begin{array}{l}\text { RPP results } \\
\quad(\text { MVAr) }\end{array}$ & EEP results (\%) & $\begin{array}{c}\mathrm{CO}_{2} \text { emission } \\
\text { reduction } \\
\left(10^{6} \mathrm{~kg}\right)\end{array}$ \\
\hline$P 1$ (2020-2025) & $n_{20-21}=1$ & $\begin{array}{c}Q_{2}=59, Q_{4}=182, Q_{5}=138 \\
Q_{9}=269, Q_{20}=458, Q_{21}=488 \\
Q_{23}=133\end{array}$ & $\begin{array}{c}\mathrm{EEP}_{5}=1.0, \mathrm{EEP}_{13}=0.8 \\
\mathrm{EEP}_{20}=1.8, \mathrm{EEP}_{24}=1.2 \\
\mathrm{EEP}_{42}=0.6\end{array}$ & 1084.5 \\
\hline$P 2(2025-2030)$ & $n_{42-43}=1$ & $\begin{array}{c}Q_{40}=21 \\
Q_{42}=155, Q_{43}=170 \\
Q_{44}=50, Q_{45}=22\end{array}$ & $\begin{array}{c}\mathrm{EEP}_{5}=0.8, \mathrm{EEP}_{13}=0.6, \mathrm{EEP}_{20}=0.6 \\
\mathrm{EEP}_{24}=1.6, \mathrm{EEP}_{42}=1.8\end{array}$ & 1288.7 \\
\hline P3 (2030-2035) & $\begin{array}{l}n_{9-14}=1 \\
n_{5-11}=1\end{array}$ & $\begin{array}{c}Q_{5}=90, Q_{9}=66, Q_{13}=60 \\
Q_{18}=47, Q_{24}=16, Q_{33}=140\end{array}$ & $\begin{array}{c}\mathrm{EEP}_{5}=0.4, \mathrm{EEP}_{13}=0.6, \mathrm{EEP}_{20}=1.2 \\
\mathrm{EEP}_{24}=1.6, \mathrm{EEP}_{42}=1.8\end{array}$ & 1443.3 \\
\hline P4 (2035-2040) & $n_{13-18}=1$ & $\begin{array}{c}Q_{5}=146, Q_{13}=187, Q_{18}=320 \\
Q_{20}=250, Q_{21}=130, Q_{23}=125 \\
Q_{24}=30, Q_{33}=130, Q_{38}=40\end{array}$ & $\begin{array}{c}\mathrm{EEP}_{5}=0.6, \mathrm{EEP}_{13}=0.2, \mathrm{EEP}_{20}=0.4 \\
\mathrm{EEP}_{24}=0.6, \mathrm{EEP}_{42}=1.0\end{array}$ & 699.9 \\
\hline
\end{tabular}


Table 4 shows $\mathrm{CO}_{2}$ reduction at each planning stage; for example, in the first stage $P 1$, by implementing the proposed approach, results show that seven reactive sources should be installed at load buses with the total capacity of 1627 MVAr, and also one line on path 2021 is added to the existing network. The following buses participate in energy efficiency programs: 5,13 , 20,24 , and 42 . In this case, the investment costs of lines and reactive resources are about M\$US31.62 and M\$US12.81, respectively. In addition, the pollution caused by carbon dioxide gas has decreased by more than 1.288 million tons. Since it is a multi-stage planning solution, the lines and reactive resources are added in $P 1$ participating in the objective function with their true values, whereas those added in $P 2, P 3$, and $P 4$ are multiplied by their corresponding factors of $0.59,0.35$ and 0.206 , respectively. However, in [35], for a single-stage planning model, the investment costs of lines and reactive sources were about M $\$$ US47.48 and M\$US14.136, respectively, showing $28 \%$ higher costs.

\section{Conclusion}

In this paper, a robust mixed-integer structure for multi-stage TEP\&RPP problems was modeled to illustrate the possibility of postponing the investment costs in planning problems. In the proposed methodology, an AC model for multi-stage planning was employed to assess the loss of real and reactive powers properly. In addition, purchasing CERs and shared saving model were proposed as incentive-based support schemes to increase the penetration rate of the EEPs in the electricity system. Regarding incentive policies, investors were encouraged to invest in such resources. One of the major achievements of this study was that solving TEP and RPP simultaneously in the presence of EEP provided better technical and economical solutions than the existing traditional planning models. The proposed multi-stage TEP\&RPP algorithm was tested on a commonly used test system, the so-called Garver system, and a practical power system, named 46-bus south Brazilian system. It was concluded that by investing in EEPs, not only was the total investment in transmission network expansion reduced, but also a significant reduction in the emission was achieved. It can be also deduced that simultaneous consideration of EEPs and multi-stage TEP\&RPP problems considerably reduced the total TEP\&RPP investment costs by preventing or postponing the construction of unnecessary lines. All in all, the results of various case studies, compared with the results presented in one of the most prominent sources in this field, indicate the effectiveness of the proposed methodology. Moreover, the robustness of the performance of the proposed approach was verified by solving a practical large-scale system.

\section{Nomenclature}

$v_{0} \quad$ Transmission lines investment

$n \quad$ New lines vector

$p_{\text {Loss }} \quad$ Total real power loss

$V \quad$ Voltage magnitude of buses

$\theta \quad$ Voltage phase angle of buses

$P_{G} \quad$ Vector of active power generation

$P_{D} \quad$ Vector of active power demand

$Q_{G}^{0} \quad$ Vector of reactive power of the existing generators

$Q_{D} \quad$ Vector of reactive power demand

$\underline{P_{G}} \quad$ Vector of lower bound of generators active power

$\bar{P}_{G} \quad$ Vector of the upper bound of generators active power

$\underline{V}$

$\bar{V}$

Minimum limit of buses voltage

Maximum limit of buses voltage

The vector of the (MVA) power flow

$S$

$N$

$N^{0}$

$S^{\text {from }}$

$S^{t o}$

$\bar{S}$

$\bar{n}$

$g_{i j}$

$\theta_{i j}$

$\Omega_{d}$

$N_{B}$

$b_{i j}$

$b_{i j}^{s h}$

$b_{i}^{s h}$

$f^{C E R}$

$V_{G}$

$I_{G} \quad$ Vector of current at the generator buses

$Q_{G} \quad$ The size of new VAr plants

$Q_{G d} \quad$ The size of a VAr source installed at bus $d$ 
$u_{d} \quad$ A binary variable that indicates whether or not to install a reactive source at the bus $d$.

$c_{0 d} \quad$ Reactive source installation cost at the bus $d$

$c_{1 d} \quad$ Reactive source unit cost at the bus $d$

$d \quad$ Index of demand buses

$\underline{Q}_{G} \quad$ The vector of VAr plants minimum limitation

$\bar{Q}_{G}$

$\bar{Q}_{G}^{0}$

$\underline{Q}_{G}^{0}$

$u$

The vector of VAr plants maximum limitation

The vector of existing VAr plants minimum limitation

The vector of existing VAr plants maximum limitation

A binary vector that indicates whether or not to install reactive power sources at demand buses

$\delta_{i n v}^{T} \quad$ Present values factor of investment in stage $t$

$E E I_{t} \quad$ The energy efficiency investment in year $t$

$E_{t} \quad$ The electricity consumption in year $t$

$E E I_{0 i} \quad$ The initial energy efficiency investment from the $i$ th program

$E S_{i, t}^{\max } \quad$ The maximum limit of energy saving from the $i$ th program in year $t$

$C E S_{i, t} \quad$ Cumulative energy saving from the $i$ th program in year $t$

$\delta_{i, t} \quad$ Energy efficiency investment elasticity

$M C_{i, t} \quad$ Marginal cost of the $i$ th program in year $t$

$C E R \quad$ Certified emission reductions price

$E M F_{C O 2} \quad \mathrm{CO}_{2}$ emission reduction

$f^{C E R} \quad$ The function of purchasing certified emission reductions from EEPs

$S S C \quad$ The sharing coefficient

$P^{E E P} \quad$ The amount of power that the EEPs can reduce in a given period

$E E P_{i} \quad$ The percentage of power that the EEPs can reduce at the bus $i$

\section{References}

1. Alvarez, F. and Rudnick, H. "Impact of energy efficiency incentives on electricity distribution companies", IEEE Trans Power Syst., 25(4), pp. 1865-1872 (2010).

2. Goldman, C., Reid, M., Levy, R., et al. "Coordination of Energy efficiency and demand response", Lawrence Berkeley National Laboratory-3044E, CA (US) (2010).
3. Baatz, B., Grace, R., and Seth, N. "The role of energy efficiency in a distributed energy future", Electr. J., 31(10), pp. 13-19 (2018).

4. Erol-Kantarci, M. and Mouftah, H.T. "Energy-efficient information and communication infrastructures in the smart grid: a survey on interactions and open issues", IEEE Commun Surv Tutorials, 17(1), pp. 179-97 (2015).

5. Vieira, N., Nogueira, L., and Haddad, J. "An assessment of $\mathrm{CO} 2$ emissions avoided by energy-efficiency programs: a general methodology and a case study in Brazil", Energy, 142, pp. 702-715 (2018).

6. Bukarica, V. and Tomšić, Z. "Energy efficiency policy evaluation by moving from techno-economic towards whole society perspective on energy efficiency market", Renew Sust Energ Rev., 70, pp. 968-975 (2017).

7. Can, S., Pudleiner, D., and Pielli, K. "Energy efficiency as a means to expand energy access: A Uganda roadmap", Energy Policy, 120, pp. 354-364 (2018).

8. Tajudeen, I., Wossink, A., and Banerjee, P. "How significant is energy efficiency to mitigate $\mathrm{CO} 2$ emissions? Evidence from OECD countries", Energy Econ., 72, pp. 200-221 (2018).

9. Ghaderi, A., Parsa Moghaddam, M., and Sheikh-ElEslami, M. "Energy efficiency resource modeling in generation expansion planning", Energy, 68, pp. 529537 (2014).

10. Yang, F. and Li, Z. "Improve distribution system energy efficiency with coordinated reactive power control", IEEE Trans Power Syst., 31(4), pp. 2518-2525 (2016).

11. Dorahaki, S., Rashidinejad, M., Abdollahi, A., et al. "A novel two-stage structure for coordination of energy efficiency and demand response in the smart grid environment", Int J Elec Power, 97, pp. 353-362 (2018).

12. Chowdhury, J., Hu, Y., Haltas, I., et al. "Reducing industrial energy demand in the UK: A review of energy efficiency technologies and energy saving potential in selected sectors", Renew Sust Energ Rev., 94, pp. 1153-1178 (2018).

13. Tengfei, M., Junyong, W., Liangliang, H., et al. "The optimal structure planning and energy management strategies of smart multi energy systems", Energy, 160, pp. 122-141 (2018).

14. Habibi, M. R., Rashidinejad, M., and Abdollahi, A. "A new adequacy evaluation method for transmission expansion planning problems", Sci. Iran., 23(3), pp. 1310-1317 (2016).

15. Habibi, M.R., Rashidinejad, M., Hajebrahimi, A., et al. "A less-effort method for spatial network planning", Sci. Iran., 25(3), pp. 1478-1491 (2018).

16. Pezzini, P., Gomis-Bellmunt, O., and Sudrià-Andreu, A. "Optimization techniques to improve energy effi- 
ciency in power systems", Renew. Sust. Energ., 15, pp. 2028-2041 (2011).

17. Zhang, H., Cheng, H., Lu, L., et al. "Coordination of generation, transmission and reactive power sources expansion planning with high penetration of wind power", Int J Elec Power, 108, pp. 191-203 (2019).

18. Yazdaninejadi, A., Hamidi, A., Golshannavaz, S. et al. "Impact of inverter-based DERs integration on protection, control, operation, and planning of electrical distribution grids", Electr. J., 32, pp. 43-56 (2019).

19. Gomes, P. and Saraiva, J. "State-of-the-art of transmission expansion planning: A survey from restructuring to renewable and distributed electricity markets", Int J Elec Power, 111, pp. 411-424 (2019).

20. Ribeiro, D. "Developments in local energy efficiency policy: A review of recent progress and research", Renew. Sustain. Energy Rev., 5, pp. 109-115 (2018).

21. Motie, S., Keynia, F., Ranjbar, M.R., et al. "Generation expansion planning by considering energyefficiency programs in a competitive environment", Int. Electr., Power Energy Syst., 80, pp. 109-118 (2016).

22. Fernando, V.C., Pourakbari-Kasmaei, M., Contreras, J., et al. "Optimal selection of navigation modes of HEVs considering CO2 emissions reduction", IEEE Trans. Veh. Technol, 68(3), pp. 446-452 (2019).

23. Alessio, P., Chiara, D., Paola. D., et al. "Energy benefit assessment of a water loop heat pump system integrated with a CO2 commercial refrigeration unit", Energy Procedia., 123, pp. 36-45 (2017).

24. Molina, M., Kiker, P., and Nowak, S. "The greatest energy story you haven't heard: How investing in energy efficiency changed the US power sector and gave us a tool to tackle climate change", ACEEE, Washington, DC, August 19 (2016).

25. Liu, Y. "Demand response and energy efficiency in the capacity resource procurement: case studies of forward capacity markets in ISO New England PJM and Great Britain", Energy Policy, 100, pp. 271-282 (2017).

26. Choi, J.K., Eom, J., and McClory, E. "Economic and environmental impacts of local utility-delivered industrial energy-efficiency rebate programs", Energy Policy, 123, pp. 289-298 (2018).

27. Freire-González, J., Vivanco, D.F., and Ventosa, I.P. "Economic structure and energy savings from energy efficiency in households", Ecol. Econ., 131, pp. 12-20 (2017).

28. Koop, G. and Tole, L. "Modeling the relationship between European carbon permits and certified emission reductions", J Empir Finance, 24, pp. 166-181 (2013).

29. Schleich, J., Rogge, K., and Betz, R. "Incentives for energy efficiency in the EU emissions trading scheme", Energy Effic., 2, pp. 37-67 (2009).

30. Brennan, T.J. and Palmer, K.L. "Energy efficiency re- source standards: economics and policy", Util. Policy., 25, pp. 58-68 (2013).

31. Komsan, K., Siritaratiwat, A., Surawanitkun, C., et al. "A novel method for solving multi-stage distribution substation expansion planning", Energy Procedia, 156, pp. 371-383 (2019).

32. Sum-Im, T., Taylor, G.A., Irving, M.R., et al. "A differential evolution algorithm for multistage transmission expansion planning", 42nd International Universities Power Engineering Conference, Brighton, UK (2007).

33. Ioannou, A., Gulistiani, F., Brennan, F., et al. "Multistage stochastic optimization framework for power generation system planning integrating hybrid uncertainty modelling", Energy Econ., 80, pp. 760-776 (2019).

34. Shen, X., Shahidehpour, M., Zhu, S., et al. "Multistage planning of active distribution networks considering the co-optimization of operation strategies", IEEE T Smart Grid, 9(2), pp. 1425-1433 (2018).

35. Rahmani, M., Rashidinejad, M., and Romero, R. "Efficient method for AC transmission network expansion planning", Electr Power Sys Res., 80, pp. 1056-1064 (2010).

36. Fourer, R., Gay, D.M., and Kernighan, B.W. "AMPL: A modeling language for mathematical programming", Pacific Grove, CA, USA, Brooks/Cole, Nov. [Online]. Available: https://ampl.com/ (2018).

37. Mahmoudabadi, A. and Rashidinejad, M. "An application of the hybrid heuristic method to solve concurrent transmission network expansion and reactive power planning", Int J Elec Power, 45, pp. 71-77 (2013).

\section{Biographies}

Amin Mahmoudabadi was born in Sirjan, Iran in 1986. He received BSc degree from Shahid Bahonar University of Kerman, Kerman, Iran in 2009 and MSc degree in Electrical Engineering in 2011. He is now working for $\mathrm{PhD}$ degree at the Electrical Engineering Department of Kerman Graduate University of Technology (KGUT). His research interests include power system planning, power system optimization, and power system operation.

Masoud Rashidinejad received BSc degree in Electrical Engineering, MSc degree in Systems Engineering, Isfahan University of Technology, Isfahan, Iran, and $\mathrm{PhD}$ degree in Electrical Engineering from Brunel University, London, U.K. in 2000. He is currently a Professor at the Department of Electrical Engineering, Shahid Bahonar University of Kerman, Kerman, Iran. His current research interests include power system optimization, power system planning, electricity restructuring, and energy management.

Amir Abdollahi received BSc degree from Shahid Bahonar University of Kerman, Kerman, Iran in 2007, 
MSc degree from Sharif University of Technology, Tehran, Iran in 2009, and PhD degree from Tarbiat Modares University, Tehran, Iran in 2012, all in Electrical Engineering. He is currently an Assistant Professor at the Department of Electrical Engineering, Shahid Bahonar University of Kerman, Iran. His research interests include demand-side management, planning, reliability, and economics in smart electricity grids. 